\title{
Effect of weaning age on growth rates of lambs infected by gastrointestinal parasites
}

\author{
R.A. DYNES, R.A. MOSS, A.R. BRAY ${ }^{1}$ and R.W. McANULTY ${ }^{2}$ \\ AgResearch, Canterbury Agriculture and Science Centre, PO Box 60, Lincoln \\ ${ }^{1}$ Meat \& Wool New Zealand, PO Box 121 Wellington \\ ${ }^{2}$ Agricutlure and Life Sciences, Lincoln University, PO Box 84 Lincoln University
}

robyn.dynes@agresearch.co.nz

\begin{abstract}
Gastrointestinal parasitism is one of the most important challenges facing low chemical or organic livestock production systems but also conventional farmers as resistance to anthelmintics becomes more widespread. Young twin-born and reared lambs were challenged for 5 days (Experiment 1 ) or trickle infected with parasites (Experiment 2) and not weaned (Expt. 1. only) or early ( 8 and 7 weeks) or late weaned (16 and 14 weeks; Expt. $1 \& 2$ respectively). Liveweight gain was measured until lambs were 19 weeks of age (Expt. 1) or 25 weeks of age (Expt. 2). Early weaning (7-8 weeks) reduced liveweight gain by at least $25 \%$ in both years and lambs remained $5 \mathrm{~kg}$ lighter at the completion of the experiments. Parasite infection had modest effects on lamb performance and there was no interaction between weaning age and parasite infection in either year. Infected lambs generally grew well, gaining at least $90 \mathrm{~g} / \mathrm{d}$ possibly due to the relatively young age of the lambs limiting their ability to mount an immune response.
\end{abstract}

Keywords: gastrointestinal parasites, low chemical, organic livestock production, sheep, growth rates

\section{Introduction}

Farmers report satisfactory lamb growth rates in organic sheep systems and conventional systems which minimise drench use (low chemical) during the lactation period but problems occur post-weaning (Mackay et al. 1998). An apparent surge in gastrointestinal parasite populations and/or pathogenicity is blamed for low growth rates. Anthelmintic treatment for welfare reasons and poor growth rates is common on conventionally managed farms, especially in autumn, coinciding with peak levels on pasture (Vlassoff 1982) of the infective $\mathrm{L}_{3}$ larvae of gastro-intestinal parasites. Sub-optimal performance of growing lambs has flow-on effects with slow turn-off of finishing lambs, failure of replacements to meet mating targets and competition for limited autumn feeding resource with ewes in the pre-mating period. Regular anthelmintic treatment is not an option for farmers producing lambs to low chemical or organic specifications and other management strategies must be used.

The observation that lambs commonly fail to thrive post-weaning in organic systems, has led to the practice of late weaning. This is despite knowledge that ewe milk production in late lactation is low (Treacher and Caja 2002) and that ewes compete with their lambs for high quality components of pasture so nutritional benefits of late weaning are expected to be small. Factors influencing growth rates post weaning include feed quality and availability, need to develop a fully functional rumen, lower nutrient intake, loss of a "protective" benefit from milk, increased intake of infective larvae $\left(\mathrm{L}_{3}\right)$ from pasture and/or nutritional cost of developing the immune system. AgResearch's Natural and Organics research program has investigated each of these areas. In this paper we report on pre- and post-weaning performance from lambs in two experiments which investigated the effect of weaning age and parasite intake pre-weaning on lamb growth rates.

\section{Methods}

Two experiments were conducted, in spring-autumn 2003/04 (Experiment 1), and in spring-autumn 2004/05 (Experiment 2). Both experiments used twin lambs from dams with a common management history. All lambs were identified to dams and were tagged with a permanent ear tag within $12 \mathrm{~h}$ of birth; twin pairs and dam numbers were all recorded. From week 2 of lactation, all animals were run as a single mob grazing moderate quality mixed grass and legume pasture expected to have minimal numbers of sheep gastrointestinal parasite larvae following at least 2 years grazing by cattle only. To minimise the risk of cross-infection between treatment groups, the mob was shifted to a fresh break every 4 days, with no access to previously grazed areas. Break size was determined by feed allowance, herbage mass and percentage dead material in the sward. A generous feed allowance for each family unit (ewe plus twin lambs) was offered (12 $-15 \mathrm{~kg} \mathrm{DM} / \mathrm{d})$ to allow diet selection since dead material (48\% in Expt. 1), weeds (25\% in Expt. 2) and mature grasses (66\% in Expt. 2) were major components of the herbage mass.

In Experiment 1, twin pairs of lambs (18 lambs per group) were allocated to the same treatment group, either early weaning ( 8 weeks of age), late weaning ( 16 weeks) or no weaning (not weaned) and infected at 8 weeks, at 
Table 1 Experiment 1: Mean liveweight change (g/day) for lambs weaned early (8 weeks), late (16 weeks) or not weaned and infected with five daily doses of $144 \mathrm{~L} 3 / \mathrm{kg}$ liveweight of $T$. colubriformis and $T$. circumcinta larvae $(70: 30)$ at either 8 or 16 weeks of age. $(n=18)$.

\begin{tabular}{|c|c|c|c|c|c|}
\hline \multirow{2}{*}{ Weaning age } & \multirow{2}{*}{ Infection age } & \multicolumn{3}{|c|}{ Liveweight change $(\mathrm{g} / \mathrm{d})-$} & \multirow{2}{*}{$\begin{array}{c}\text { Final liveweight }(\mathrm{kg}) \\
19 \text { weeks }\end{array}$} \\
\hline & & Birth-7 weeks & 8-16 weeks & $16-19$ weeks & \\
\hline \multirow[t]{3}{*}{8 weeks } & Not infected & 260 & $199^{a}$ & $135^{a}$ & $31.6^{a}$ \\
\hline & & 260 & $188^{a}$ & $128^{a}$ & $31.2^{\mathrm{a}}$ \\
\hline & 16 & 260 & $192^{a}$ & $90^{a}$ & $30.2^{a}$ \\
\hline \multirow[t]{3}{*}{16 weeks } & Not infected & 269 & $285^{b}$ & $155^{\mathrm{b}}$ & $36.9^{b}$ \\
\hline & & 256 & $284^{b}$ & $124^{\mathrm{a}}$ & $36.3^{b}$ \\
\hline & 16 & 264 & $285^{b}$ & $103^{a}$ & $35.3^{b}$ \\
\hline \multirow[t]{3}{*}{ Not weaned } & Not infected & 261 & $279^{b}$ & $181^{c}$ & $37^{b}$ \\
\hline & 8 & 260 & $274^{b}$ & $161^{b c}$ & $35.9^{b}$ \\
\hline & 16 & 266 & $274^{b}$ & $160^{\mathrm{bc}}$ & $37.4^{b}$ \\
\hline \multicolumn{2}{|c|}{ Average SEM } & 6.5 & 9.6 & 13.1 & 0.85 \\
\hline
\end{tabular}

awithin a column, means with different superscripts are significantly different $(\mathrm{P}<0.05)$

Table 2 Experiment 2: Mean liveweight change (g/day) for lambs weaned early (7 weeks) or late (15 weeks) and not infected or trickle infected with T. colubriformis and T. circumcinta (60:40) during weeks 5-15 (early), weeks 16-23 (late) or both weeks 5-15 and 16-25 (early and late) $(n=12)$.

\begin{tabular}{|c|c|c|c|c|c|}
\hline \multirow{2}{*}{ Weaning age } & \multirow{2}{*}{ Infection age } & \multicolumn{3}{|c|}{ Liveweight change $(\mathrm{g} / \mathrm{d})$} & \multirow{2}{*}{$\begin{array}{l}\text { Final liveweight } \\
\text { at } 25 \text { weeks }(\mathrm{kg})\end{array}$} \\
\hline & & Birth-4 weeks & 5-15 weeks & $16-25$ weeks & \\
\hline \multirow[t]{4}{*}{7 weeks } & Not infected & 241 & $192^{a}$ & 126 & $34.1^{\mathrm{a}}$ \\
\hline & 4-14 weeks & 246 & $166^{a}$ & 139 & $34.5^{a}$ \\
\hline & $15-25$ weeks & 253 & $210^{a}$ & 117 & $35.2^{a}$ \\
\hline & Early \& late & 258 & $175^{a}$ & 117 & $34.1^{\mathrm{a}}$ \\
\hline \multirow[t]{4}{*}{14 Weeks } & Not infected & 255 & $250^{b}$ & 146 & $41.3^{b}$ \\
\hline & 4-14 weeks & 251 & $236^{b}$ & 127 & $38.9^{b}$ \\
\hline & $15-25$ weeks & 249 & $262^{b}$ & 126 & $40.5^{b}$ \\
\hline & Early \& late & 241 & $226^{b}$ & 126 & $37.6^{b}$ \\
\hline \multicolumn{2}{|c|}{ Average SEM } & 6.1 & 5.6 & 8.2 & 0.99 \\
\hline
\end{tabular}

${ }^{a}$ within a column, means with different superscripts are significantly different $(P<0.05)$

16 weeks or not infected with parasites. In Experiment 2, twin pairs of lambs (12 lambs per group) were weaned at 7 or 15 weeks of age and trickle infected early (weeks 5 to 15 ) and/or late (weeks 16-25). Weaning was achieved by removing ewes from the mob resulting in a mixed mob of weaned lambs and unweaned lambs with their dams.

In both experiments, lambs were artificially infected, with gastrointestinal parasites by oral dosing with infective larvae (stage 3 larvae: L3) suspended in water. In Experiment 1, lambs received 144 L3/kg liveweight daily over 5 days of Trichostronglyus colubriformis and Telodorsagia circumcinta larvae (70:30) at either 8 or 16 weeks of age. In Experiment 2, lambs were trickle infected with 60 infective L3 larvae/ $\mathrm{kg}$ liveweight per day of $T$. colubriformis and $T$. circumcinta $(60: 40)$ administered three times per week for periods 5 to 15 weeks and/or 16 to 25 weeks of age. Lambs ingested similar numbers of L3 as would be expected to be ingested by lambs grazing a heavily contaminated pasture for 5 days (Expt 1) or a moderately contaminated pasture continuously (Expt 2).

Liveweights of lambs and ewes and lamb faecal egg counts were monitored at regular intervals during both experiments. The number of adult gastrointestinal parasites in the abomasums and small intestine was determined at slaughter at age 11 or 19 weeks in Experiment 1 and age 15 or 25 weeks in Experiment 2. The slaughter data are not presented here.

\section{Analysis}

The effects of weaning age and timing of parasite infection on liveweight change and liveweight were determined using analysis of variance. Statistical analysis was carried out using Minitab statistical software. (Minitab v14.0).

\section{Results}

In both experiments, lambs grew about a similar rate $(255 \pm 6.3 \mathrm{~g} /$ day $)$ in the pre-experimental phase of early lactation (Tables $1 \& 2$ ).

Early weaning had the biggest impact on performance of young lambs, depressing early performance by $30 \%$ 
$(\mathrm{P}<0.001)$ in Experiment 1 (Table 1) and 24\% $(\mathrm{P}<0.001)$ in Experiment 2 (Table 2). In Experiment 1, the impacts continued to week 19 with unweaned lambs growing $30 \%$ faster from weeks 16-19 than early-weaned lambs and $24 \%$ faster than late-weaned lambs. In Experiment 2 , there was little difference in daily liveweight gain due to age of weaning after week 15 (Table 2) $(\mathrm{P}>0.05)$.

Where animals ingested parasites over 5 days (Expt. 1) lambs grew well with no significant differences in daily liveweight gain between unparasitised and parasitised lambs weaned at 8 weeks (Table 1), despite the presence of adult nematodes within the gastrointestinal tract (data not presented). Lambs weaned at 16 weeks and infected at 8 or 16 weeks grew at a similar rate as unweaned lambs except during the final 3 weeks of measurement when growth was depressed by around $40 \mathrm{~g} /$ day. Final liveweight of animals was only affected by early weaning with no effects of late weaning or parasites. There were no interactions during any growth period between age at weaning, parasite treatment and liveweight change.

Trickle infection in Experiment 2 depressed daily liveweight gain by $12 \%(20 \mathrm{~g} /$ day $)(\mathrm{P}<0.001)$ in lambs between 5 and 15 weeks of age and a non-significant $8 \%$ during weeks 16-25 (Table 2), despite a substantial number of adult parasites in the gastrointestinal tract of all lambs at this time (results not presented). When uninfected during weeks 5-15, growth of late weaned lambs was $15 \%$ faster $(\mathrm{P}<0.05)$ during weeks $16-25$ than early weaned lambs. Late weaned, infected lambs grew $6 \%$ slower at this time than early weaned, infected lambs. Weaning age accounted for most of the differences in liveweight in Experiment 2, with a $5 \mathrm{~kg}$ difference in liveweight between early and late weaning ( 34.5 vs 39.6 $\mathrm{kg}$ ) while early parasite infection depressed liveweight by $1.5 \mathrm{~kg}(37.8$ v $36.3 \mathrm{~kg})$.

\section{Discussion}

Weaning age and trickle infection by gastrointestinal parasites both depressed early performance of lambs, but there was no interaction between weaning age and parasite infection status.

Early weaning was used as a tool to investigate the effect of gastrointestinal parasites on young lambs with and without milk intake. Early weaning had a major impact on performance of young, light animals as found in earlier studies (Rattray et al. 1976; Geenty 1980) but little or no effect on heavier lambs weaned on good quality forage. Lambs failed to compensate for the significant early setbacks from lack of milk within the duration of either study and any later compensation will be limited (Bray et al. 1990). Performance was likely to have been further disadvantaged by competition for high quality components of pasture from remaining ewes in mob and limited opportunities for high quality feed in the 'clean' pastures. In addition, especially in Experiment 2 when lambs were weaned at 7 weeks of age, rumen development may have been incomplete since the rumen develops to adult proportions usually from weeks 3-8 (Wardrop \& Coombe 1961) depending on availability of solid feed. A weaning age of 16 weeks was used to replicate delayed weaning in Experiment 1 and it was planned to wean at 14 weeks in Experiment 2. However, a compact lambing spread resulted in the true average age of lambs in Experiment 2 being 15 weeks, which is later than 12-14 weeks common in industry.

Despite the substantial impacts on lamb growth rates from early weaning, neither a single challenge nor trickle challenge resulted in a clear interaction between parasite infections and weaning age (milk intake) that affected liveweight gain. A limitation of this type of field study was the use of liveweight gain rather than nutritional parameters which may have demonstrated an interaction. The apparent benefits in growth rate during weeks 16 to 19 to not weaning animals in Experiment 1 must be viewed with caution since it was relatively short term and the higher growth rate did not convert to a liveweight difference at week 19 .

Even when lambs were continually exposed to parasites with trickle infection, we could not demonstrate an interaction between weaning age/milk removal and performance under parasite challenge. Losses in growth due to parasites were modest and were less than an indoor study reported by Steel et al. (1982) using mixed infections at three times the dose used in the current study. Depression in growth rates were also much smaller than reported by Kimambo et al. (1988) who found a severe growth check (90\%) between 6 and 13 weeks after infection with $T$. colubriformis although animals returned to normal growth pattern after acquisition of immunity. In grazing experiments using natural infection, McAnulty et al. (1982) found lambs on 'clean' pastures grew $35 \%$ faster than lambs on contaminated pasture, again a larger difference than found here.

Lambs in the current experiment were much younger at the time of infection ( 8 and 5 weeks of age) than those used in other published work, e.g. 10 and 12 weeks (McAnulty et al. 1982) 15 weeks (Steel et al. 1982) and 20 weeks (Kimambo et al. 1988). Recent suggestions that the real cost of parasites is in the cost of the immune response (Sykes \& Greer 2003), which changes the priority of nutrient partitioning from growth to host defence (Colditz 2002), may be relevant here. A lack of a significant immune response in these young lambs could explain the modest depression in performance due to parasites. That is, the lambs may have grown well because they were not physiologically able to mount an 
immune response or they were mounting a 'lower cost' immune response. A later publication will consider the implications for acquired immunity from this early exposure to parasites and level of immunity acquired by these young lambs.

Weaned lambs no longer have the additional energy and secondary compounds available from milk, yet these lambs were apparently proportionately no worse off under either single or continuous ingestion of gastrointestinal parasites than milk fed flock mates. Late weaning of calves was demonstrated by Boom et al. (2004) as a useful strategy to reduce reliance on anthelmintics and maintain good liveweight gain, although the authors could not determine to what extent the milk effect was protective or due to additional nutrients. Late weaned lambs must compete with ewes for highest quality components of pasture. Rather than leaving lambs unweaned in the hope of resilience to parasites, strategies to minimise any postweaning check and subsequent grazing of high quality pastures with low levels of larval contamination may produce the best system outcomes.

\section{ACKNOWLEDGEMENTS}

The authors acknowledge Westlea Clarke, Trevor Knight Dennis O'Connell, Keith Hewitt and Christina Lima for skilled technical assistance and Dave Saville for statistical advice. This work was funded under FRST contract C10X0236 "Natural and Organic".

\section{REFERENCES}

Boom, C.J.; Sheath, G.W; Vlassoff, A. 2004. The effect of weaning date, gastro-intestinal nematode challenge and nutrition on beef calf growth. Proceedings of New Zealand Society of Animal Production 64: 257-261.

Bray, A.R.; Moss, R.A.; Burton, R.N.; Saville, D.J. 1990. Postweaning growth and carcass leanness of lambs that differed in preweaning growth rate. Proceedings of New Zealand Society of Animal Production 50: 287-291.

Colditz, I.G. 2002. Effects of the immune system on metabolism: implications for production and disease resistance in livestock. Livestock Production Science 75: $257-268$.
Geenty, K.G. 1980. Influence of weaning age, management and slaughter age on export lamb carcass production and slipe wool weights. New Zealand Journal of Agricultural Research 23: 433-440.

Kimambo, A.E.; MacRae, J.A.; Walker, A.; Watt, C.F.; Coop, R.L. 1988. Effect of prolonged subclinical infection with Trichostrongylus colubriformis on the performance and nitrogen metabolism of growing lambs. Veterinary Parasitology 28: 191-203.

Mackay, A.D. Betteridge K.; Devantier, B.J.; Budding, P.J.; Niezen, J.H. 1998. Chemical-free hill country sheep and beef livestock production systems. Proceedings of the New Zealand Grasslands Association 60: 15-18.

McAnulty, R.W.; Clark, V.R.; Sykes, A.R. 1982. The effect of clean pasture and anthelmintics frequency on growth rates of lambs on irrigated pasture. Proceedings of New Zealand Society of Animal Production 42: 187188.

Rattray, P.V.; Morrison, M.C.L.; Farquhar, P.A. 1976. Performance of early-weaned lambs on lucerne and pasture. Proceedings of New Zealand Society of Animal Production 36: 179-183.

Steel, J.W.; Jones, W.O.; Symons, L.E.A. 1982. Effects of a concurrent infection of Trichostrongylus colubriformis on the productivity and physiological and metabolic responses of lambs infected with Ostertagia circumcinta. Australian Journal of Agricultural Research 33: 131-140.

Sykes, A.R.; Greer, A.E. 2003. Effects of parasitism on the nutrient economy of sheep: an overview. Australian Journal of Experimental Agriculture 43: 1393-1398.

Treacher, T.T.; Caja, G. 2002. Nutrition during lactation. In: Sheep nutrition. Eds. Freer, M.H. Dove, H. CSIRO Publishing, Australia.

Vlassoff, A.1982. Biology and population dynamics of the free-living stages of gastrointestinal nematodes of sheep. pp 11-20 In: Internal parasites of sheep. Animal Industries Workshop, Ed Ross A.D. Lincoln College, 1982.

Wardrop, I.D.; Coombe, J.B. 1961. The development of rumen function in the lamb. Australian Journal of Agricultural Research 12: 661-680. 